\title{
Nosodentherapie, Dr. Sauerbruch und der Zauber der Jugend
}

\author{
Im Tierreich wird sie von der Mutter meist verspeist, in China wird sie für ca. \\ 50 Euro gehandelt und im Internet ist sie Bestandteil unzähliger Smoothie- \\ Rezepte: die Plazenta, auch Mutterkuchen oder Nachgeburt genannt.
}

Die Plazenta ist seit dem Altertum von einem besonderen Mythos umgeben und gilt als das Seelenpendant des Neugeborenen. Das Besondere: Sie besteht sowohl aus embryonalem sowie mütterlichem Gewebe. Sie versorgt das Ungeborene, den Fötus, über die Nabelschnur mit Sauerstoff und Nährstoffen und filtert Schadstoffe - ähnlich wie unsere Leber. Sie ist reich an B-Vitaminen, Eisen und wichtigen Hormonen. Sie produziert Östrogene, Gestagene, das Schwangerschaftshormon (HCG) und das milchfördernde Hormon Plazentalaktogen (hPL). Daher soll der Verzehr von Plazentagewebe Wochenbettdepressionen vorbeugen oder lindern, die Milchproduktion fördern und für einen schönen Hautteint sorgen.

Bereits seit der Antike wird der Mutterkuchen gekocht, getrocknet und zu Pulver vermahlen. In der Volksmedizin soll sie nicht nur der Mutter und dem Neugeborenen helfen, sondern auch den Geschwisterkindern und dem Vater. Daher war Plazenta-Pulver bis in die Mitte des 20. Jahrhunderts in vielen Haushalten zu finden.

\section{Noso... - was?}

Aber noch heute ist es möglich, die eigene Plazenta nach der Geburt als sogenannte Plazentanosode verarbeiten zu lassen. Dazu wird ein kleines Stückchen der Plazenta entnommen. In einem spezialisierten Labor oder Apotheke wird das Gewebe nach den Prinzipien der Homöopathie „energetisch aufgewertet" und in verschiedenen Potenzen zu Globuli, Salbe, Tropfen verarbeitet. Zum Anwendungsgebiet gehören alle regulatorischen
Prozesse des Organismus. So kann ein geschwächtes Immunsystem gestärkt werden, während eine überschießende Immunantwort beispielsweise im Rahmen einer Allergie abgemildert werden soll. Zugleich finden die Plazentanosoden auch Anwendung bei Migräne, Neurodermitis und hormonellen Dysbalancen wie Menstruations- oder Wechseljahresbeschwerden.

Die sogenannte Nosodentherapie ist eine Sonderform der Homöopathie, die von dem deutsch-amerikanischen Arzt Dr. Constantin Hering um 1830 eingeführt wurde. Er gilt als Begründer der Homöopathie in Amerika und folgt Hahnemanns Ähnlichkeitsprinzip. Dieses besagt, dass Kranke mit jenen Stoffen geheilt werden können, die bei einem Gesunden genau diese Symptome auslösen würden. So gehören zur Nosodentherapie homöopathisch aufbereitete Gewebe und Sekrete, außer Plazenta-Nosoden zum Beispiel auch Zubereitungen aus (sterilisierten) Krankheitserregern oder Krebsgewebe.

\section{Zeitlos jung und faltenfrei}

Neben der Anwendung bei Krankheitszuständen werden Plazentaextrakte aber vor allem auch zur Verjüngungstherapie eingesetzt. So werden bei der umstrittenen Frischzellenoder Organotherapie häufig Plazentaextrakte verwendet, in diesem Fall meist von Schafen oder Rindern. Aufgrund mangelnder

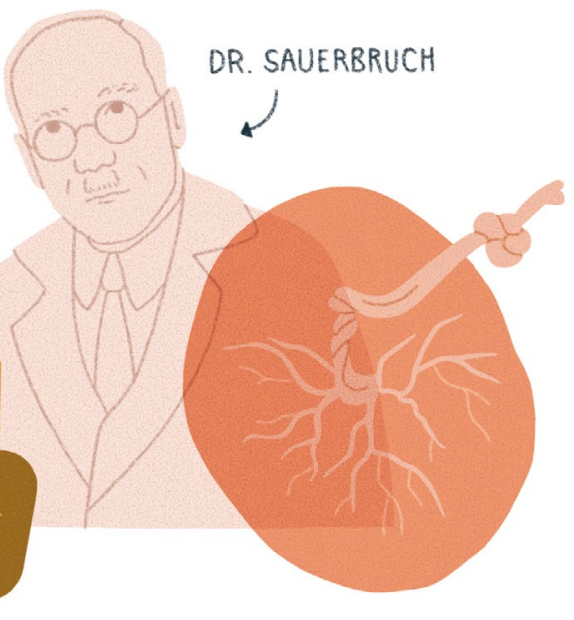

Wirksamkeitsbeweise wurden diese jedoch vom BfArM (Bundesinstitut für Arzneimittel und Medizinprodukte) als bedenklich eingestuft.

Auch die Kosmetikindustrie nutzt die Plazenta und ihre straffende Wirkung. Erklärbar ist die Wirkung durch die hochkonzentrierten Hormone, die zu einer Einlagerung von Wasser im Gewebe führen und die Haut somit straffer aussehen lassen können.

Aber was hat der Pionier der Thoraxchirurgie und Spezialist für Prothetik Dr. Ferdinand Sauerbruch damit zu tun? In den Nachkriegsjahren (1950er Jahren) entwickelte Dr. Sauerbruch für ein kleines „Start-up“ mit dem Namen „Placenta Kosmetik" exklusiv die ersten Hormocenta ${ }^{\circledR}$-Rezepturen, war elementarer Werbeträger und machte es zu einem der erfolgreichsten deutschen Kosmetikunternehmen. Zur wahren Werbeikone für Jugendlichkeit wurde allerdings erst Filmstar Marika Rökk. Mittlerweile sind Plazenta-Rezepturen in deutschen Kosmetika nicht mehr zugelassen. Wer trotzdem ein Plazenta-Luxus-Facial für den Zauber der Jugend möchte, kann sich in Dubai exklusiv behandeln lassen, Seite an Seite mit Jennifer Lopez oder Victoria Beckham - für knappe 1.000 Euro.

Dr. Andrea Jessen 